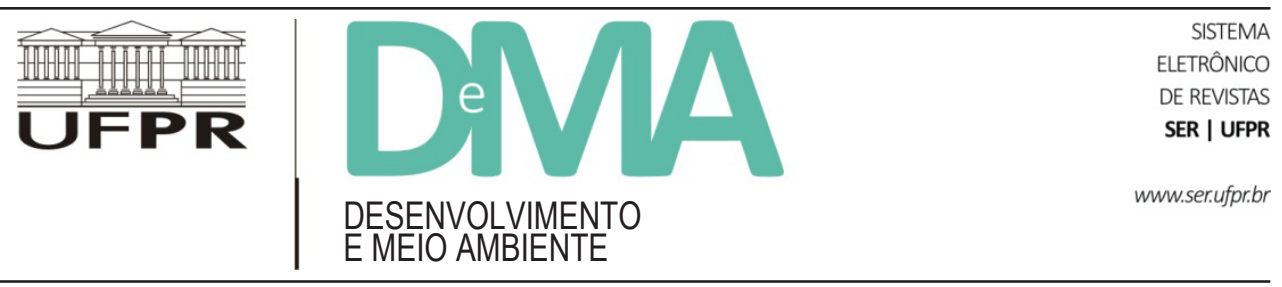

\title{
Percepção ambiental e fenomenologia: possibilidades de adaptação do método e alguns exemplos de pesquisas
}

\section{Environmental Perception and Phenomenology: Possibilities of Method Adaptation and Some Examples of Researches}

\author{
Lucas Barbosa e SOUZA ${ }^{1 *}$ \\ ${ }^{1}$ Universidade Federal do Tocantins (UFT), Palmas, TO, Brasil. \\ *E-mail de contato: lbsgeo@uft.edu.br
}

Artigo recebido em 13 de janeiro de 2016, versão final aceita em 30 de março de 2017.

RESUMO: As influências da Fenomenologia sobre os estudos de percepção ambiental são amplamente reconhecidas, embora o emprego do método fenomenológico em pesquisas aplicadas ainda constitua foco de debate, em virtude das adaptações necessárias do campo filosófico para o campo empírico. Contudo, é inquestionável a riqueza desse método para as investigações que buscam conhecer o aspecto subjetivo da relação entre os seres humanos e o meio ambiente. Com base nessa premissa, este artigo pretende discutir e demonstrar as possibilidades de condução da pesquisa ambiental perceptiva com base no emprego do método fenomenológico, considerando-se também sua articulação com técnicas convencionais de pesquisa qualitativa. Para tanto, após uma breve contextualização teórica, delineamento do método e de suas adequações, apresentam-se a trajetória de investigação e os resultados obtidos em exercícios de pesquisa realizados sob a orientação do autor.

Palavras-chave: abordagem perceptiva; método fenomenológico; pesquisa empírica qualitativa; técnicas de pesquisa.

ABSTRACT: The influences of Phenomenology on environmental perception studies are widely recognized, although the use of the phenomenological method in applied researches still constitutes a focus of debate, given the necessary adaptations from the philosophical field to the empirical field. However, the richness of this method for investigations that seek to know the subjective aspect of the relationship between humans and the environment is unquestionable. Based on this premise, this article aims at discussing and demonstrating the possibilities of conducting perceptive environmental research based on the use of the phenomenological method, as well as considering its articulation with conventional qualitative research techniques. Thus, after a brief theoretical context, the design of the method and its adaptations, the trajectory of research and the results obtained in research exercises conducted under the guidance of the author are presented.

Keywords: perceptive approach; phenomenological method; qualitative empirical research; research techniques. 


\section{Introdução}

Os estudos e as pesquisas circunscritos ao domínio da percepção ambiental convergem seus interesses à subjetividade, motivo pelo qual foram influenciados, direta ou indiretamente, pela corrente filosófica conhecida como Fenomenologia. Essa corrente teve sua origem na transição do século XIX para o XX pelas mãos de Edmund Husserl, ao longo de sua trajetória por diferentes universidades europeias, tais como as de Berlim e de Viena. As ideias de Husserl influenciaram, posteriormente, outros filósofos que, por sua vez, fizeram novas leituras e interpretações da Fenomenologia, como nos casos de Heidegger e de Merleau-Ponty (Giorgi, 2008; Andrade \& Holanda, 2010).

Considera-se inequívoca a influência do pensamento fenomenológico sobre o campo da percepção ambiental, podendo-se constatar inúmeras convergências, a começar pela constituição dos conceitos centrais, pelo foco na subjetividade e pelo interesse sobre as vivências humanas (Ribeiro et al., 2009; Souza, 2013). Todavia, a inserção da Fenomenologia nos estudos perceptivos do meio ambiente não se deu por completo, especialmente se considerada em termos de método, de modo semelhante ao que foi apontado por Pickles (1985) e por Holzer (1998) no campo da Geografia.

Conforme Stein (2004, p. 130), “[...] a questão do método na Filosofia possui características radicalmente distintas do método que conduz os preceitos da Ciência". Nessa perspectiva, o método fenomenológico, originalmente concebido por Husserl como caminho para a investigação filosófica, desafiou estudiosos posteriores, no sentido de realizar sua transposição para o domínio da pesquisa empírica (Gil, 2010). Essa transposição norteou-se, inicialmente, pelo deslocamento do foco para a consciência e as vivências alheias ao pesquisador, ou seja, um foco orientado aos fenômenos que se manifestam aos sujeitos que integram o corpus empírico de determinada pesquisa. Nesse sentido, deixa de ser um método pessoal, pois que visa conhecer a experiência do outro, na maioria das vezes, por meio de seus relatos (Moreira, 2002).

Tal esforço de transposição foi empreendido, entre outros nomes, por Giorgi $(1985 ; 2008)$, na tentativa de empregar o método fenomenológico em pesquisas empíricas qualitativas, mais especialmente no ramo da Psicologia (Moreira, 2002; Gil, 2010; Andrade \& Holanda, 2010). Todavia, a contribuição de Giorgi $(1985$; 2008) para a construção de uma trajetória metodológica em Fenomenologia Descritiva não se limita ao seu próprio campo de atuação, podendo estender-se a outros ramos científicos, notadamente aqueles interessados em estudos com viés humanístico ou humanista, como a percepção ambiental.

Em termos de orientação metodológica, Whyte (1977), com um guia para estudos de campo, destacou-se especificamente no âmbito da percepção ambiental. Os procedimentos e técnicas constantes em tal guia foram baseados em três tipos de estratégias: ouvindo, perguntando e observando. Esse guia orientou e ainda orienta inúmeros trabalhos nessa área, a exemplo de várias pesquisas realizadas no Brasil desde a década de 1980 (Del Rio \& Oliveira, 1999).

Considerando a abordagem de Whyte (1977), enfatizamos o papel da estratégia "ouvindo", sobretudo como ponto de partida das investigações. Trata-se da ocasião para que os sujeitos possam manifestar-se livremente e revelar os sentidos de suas percepções antes que o olhar do pesquisador os inquira com indagações, constituídas a partir de sua própria percepção sobre o fenômeno. É especialmente nesse ponto que se visualiza a possibilidade de aplicação do método fenomenológico, como forma de ouvir e, 
consequentemente, de compreender os participantes dos estudos perceptivos sobre o meio ambiente.

Sendo assim, o presente artigo traz uma reflexão introdutória a respeito do emprego do método fenomenológico nas pesquisas em percepção ambiental, tomando como referência o método de Giorgi (1985; 2008). Apresenta, também, alguns exemplos da operacionalização do método em estudos aplicados e apontamentos sobre as possibilidades de articulação da abordagem fenomenológica com outras estratégias de investigação. Trata-se, pois, de um trabalho com característica exploratória e cunho metodológico, fruto de exercícios recentes realizados pelo autor, juntamente com seus orientandos.

\section{Aspectos do método fenomenológico e sua relação com a percepção ambiental}

A Fenomenologia, conforme originalmente articulada por Husserl, tem como propósito o estudo da manifestação dos fenômenos à consciência, o que se dá por meio das diferentes vivências do ser humano. Entre essas vivências, encontra-se não somente a percepção, mas também a lembrança, a imaginação e a reflexão, que constituem atos decorrentes de nossa estrutura transcendental (Bello, 2004).

$\mathrm{O}$ método fenomenológico diz respeito ao caminho concebido por Husserl para o estudo desses fenômenos presentes na consciência, o que pressupõe um enfoque sobre a sua dimensão de essência ou ideia e não sobre a sua existência concreta. Por conseguinte, trata-se de um método voltado ao estudo da subjetividade, uma vez que centra seu interesse sobre os fenômenos enquanto percebidos, lembrados, imaginados ou refletidos, por sua vez, correlatos imanentes (internos) de fenômenos factuais, situados fora da consciência (Bello, 2004; 2006; Husserl, 2006; Depraz, 2008).
Para Husserl, o método fenomenológico está fundamentado em reduções que suprimem tanto a dimensão concreta dos fenômenos quanto os prejulgamentos e hipóteses que se possam ter sobre eles. Para Bello (2004; 2006), essas supressões estão circunscritas aos campos da redução eidética (ou à essência) e da redução transcendental (ou ao sujeito), que, segundo essa autora, constituem as duas etapas típicas do método fenomenológico.

$\mathrm{O}$ emprego de tal método pressupõe, desse modo, a mudança de uma atitude dita natural (que toma o mundo como algo dado) para uma atitude filosófica ou fenomenológica, olhando "para" o que habitualmente olhamos "por intermédio" (Sokolowski, 2004, p. 59). Tal postura é a que, possivelmente, tenha levado Merleau-Ponty (1999, p. 19), no prefácio de sua "Fenomenologia da percepção", a afirmar que "a verdadeira filosofia é reaprender a ver o mundo [...]".

Assim como declararam Pickles (1985), Holzer (1998) e Nogueira (2008), a Geografia Humanista e, por dedução, os estudos de percepção ambiental nela circunscritos acabaram por utilizar, apenas de maneira implícita, o método fenomenológico, eximindo-se de seu emprego de modo rigoroso e direto. Tal opção, possivelmente, esteve vinculada às dificuldades de uso de um método construído originalmente com vistas à investigação filosófica e, portanto, voltado ao raciocínio "pessoal” e não à pesquisa empírica (Moreira, 2002, p. 103).

Essa transposição do caráter filosófico para o empírico, por seu turno, foi sendo esboçada gradualmente ao longo do século XX, principalmente em sua segunda metade, e, de forma especial, pela Psicologia (Moreira, 2002; Andrade \& Holanda, 2010). Enquanto isso, no campo dos estudos geográficos e ambientais, verificou-se, em geral, apenas a adoção de um espírito ou viés fenomenológico, a começar pelo caráter de investigação da subjeti- 
vidade (Pickles, 1985; Holzer, 1998). Para Giorgi (2008), esse tipo de aproximação se traduz em uma acepção vaga ou genérica da Fenomenologia, que basicamente confere às pesquisas somente um distanciamento daquilo que se convencionou chamar de "científico", ou seja, das investigações baseadas em critérios objetivos ou positivistas.

Todavia, a influência da escola fenomenológica no domínio da percepção ambiental se manifesta de forma clara, em especial, por meio da gênese conceitual. Na introdução de Topofilia, por exemplo, Tuan (1980) indica as principais categorias de análise, habitualmente presentes em estudos de percepção ambiental ou de percepção geográfica. Propõe, assim, um arcabouço teórico com influência nitidamente fenomenológica, ainda que sua opção declarada seja pelo Humanismo e não abertamente pela Fenomenologia, como explica Holzer (1998).

Conforme demonstrado por Souza (2013), nos próprios conceitos de percepção, de valor e atitude preconizados por Tuan (1980), encontram-se subentendidos pontos centrais do pensamento fenomenológico, tais como a questão transcendental e da intencionalidade, além dos aspectos hilético e noético, presentes nas ideias de Husserl. Ao estudar as bases fenomenológicas da Geografia, Holzer (1998) explica que a influência da Fenomenologia nos estudos geográficos remonta aos trabalhos de Carl Sauer, na década de 1920, e de Eric Dardel, na década de 1950, embora se consolide a partir da década de 1960, por intermédio de nomes como Y-fu Tuan e Edward Relph, entre outros, ainda que o emprego do método não se verifique.

O próprio Holzer (1998) buscou na Fenomenologia o aporte para uma abordagem sobre a paisagem e o lugar, segundo as crônicas dos viajantes que pioneiramente descreveram partes do Brasil no século XVI. Nesse trabalho, Holzer (1998) escolheu o método fenomenológico como referência, portanto, não apenas como uma postura alternativa àquela tipicamente positivista. Optou, todavia, por seguir um caminho fenomenológico-existencialista, explicitamente por meio da geograficidade de Dardel (2011), como marco conceitual para a compreensão da relação subjetiva do homem com seu mundo-vivido. Porém, em que pese sua importante contribuição, Holzer (1998) se mostra consciente ao afirmar que "[...] a aplicação do método fenomenológico na resolução de questões essenciais da geografia está para ser construída".

No âmbito da percepção ambiental (área de estudos também focalizada pela Geografia, mas não restrita a essa ciência), a constatação de Holzer (1998) também se mostra válida e pertinente, uma vez que, a nosso ver, permanece inconclusa a questão da adaptação e do emprego do método fenomenológico em pesquisas empíricas nesse campo. Tal adequação deve, por sua vez, levar em consideração não somente a natureza subjetiva das pesquisas, o que implica a forma de interpretação de seus resultados, mas também as especificidades ligadas aos seus propósitos pragmáticos e aos aspectos de sua operacionalidade.

De acordo com a explicação fornecida por Moreira (2002, p. 107), “[...] a pesquisa empírica apresenta um caráter de ação, que nos obriga a interagir ou com objetos materiais, ou com pessoas, ou com ambos. É necessário acomodar essa faceta pró-ativa no contexto meramente reflexivo do método fenomenológico". No campo da percepção ambiental, essas complexas relações mostram-se notavelmente desafiadoras, especialmente se abordadas pela via das particularidades do método fenomenológico.

Vislumbram-se, contudo, possibilidades de avanço por intermédio do diálogo entre geógrafos, demais estudiosos do meio ambiente e pesquisadores de outras áreas do conhecimento. A incorporação adaptada de tais perspectivas de progresso do 
método fenomenológico tem se mostrado especialmente frutífera. As viabilidades e limitações de tal empreendimento norteiam-se, pois, pelo exercício interdisciplinar entre diferentes modos pelos quais o conhecimento se (re)produz.

\section{O emprego do método fenomenológico nos estudos de percepção ambiental}

Uma das principais referências metodológicas para os estudos de percepção ambiental tem sido a pioneira obra de Whyte (1977), que sistematizou, em seu Guidelines for fields studies in environmental perception, as formas de abordagem e suas respectivas técnicas de pesquisa, assim como as variáveis passíveis de investigação nesse campo. O trabalho contribuiu para um importante avanço das pesquisas em percepção ambiental nas décadas que o sucederam, inclusive com a realização de muitos estudos no Brasil (Del Rio \& Oliveira, 1999).

Para Whyte (1977), o desenho das investigações na percepção ambiental deve ancorar-se numa espécie de triângulo metodológico, formado por três tipos distintos e complementares de abordagem: ouvindo, perguntando e observando. A escolha da melhor abordagem e, consequentemente, da melhor técnica dependerá dos objetivos da pesquisa, das condições de campo, do tempo disponível do pesquisador, da familiaridade com os sujeitos, do grau de instrução e da experiência prévia dos participantes com pesquisas semelhantes. De qualquer modo, informa Whyte (1977), sempre que possível, é desejável empregar mais de uma abordagem, para que sejam obtidas informações complementares e passíveis de cruzamento no momento de sua interpretação e análise.

Especificamente quanto ao "ouvindo", Whyte (1977) explica tratar-se do tipo de abordagem mais negligenciado pelos estudos de percepção ambiental, dada a menor concentração de pesquisas que se utilizam dessa estratégia para coleta de informações verbais. No âmbito dessa abordagem, a autora fornece o exemplo de algumas técnicas, como a caminhada (em que cada sujeito é "ouvido" durante ou após um trajeto pela área de estudo) e o diário (em que o próprio sujeito registra suas percepções diariamente, ao longo de um dado tempo), além do método da história oral, indicando possibilidades junto às quais consideramos vantajoso incluir o método fenomenológico.

Ao reconhecer o peso da abordagem "ouvindo", notadamente como ponto de partida para as investigações, é que se vislumbra a adoção do método fenomenológico como caminho revelador para o estudo da percepção ambiental, a começar pela valorização de suas raízes filosóficas. Iniciar uma pesquisa perceptiva pela escuta atenta de seus sujeitos significa minimizar os possíveis efeitos de hipóteses previamente formuladas pelo pesquisador, permitindo-se que os sentidos sejam revelados o mais espontaneamente possível pelos próprios participantes da investigação. A postura de ouvir mais e de perguntar menos nos remete, pois, ao cerne da atitude fenomenológica, ou seja, à busca pela suspensão dos apriorismos, e é nesse sentido que o método fenomenológico se ajusta aos passos iniciais da pesquisa perceptiva sobre o meio ambiente.

Contudo, novamente evocando Moreira (2002) e Gil (2010), torna-se necessário examinar com cautela a questão da passagem do método fenomenológico para o campo dos estudos empíricos. Trata-se, desse modo, de um aspecto do qual o pesquisador deve estar consciente e atento, ainda que se debruce sobre esforços previamente empreendidos por aqueles que se dedicaram à adaptação do método. De acordo com Moreira (2002, p. 107, grifo nosso), “A passagem direta de um método da 
Filosofia para a pesquisa empírica, por se tratar de campos de reflexão tão diferentes, não poderá e não deverá dar-se de forma simples, sem concessões e adaptações".

No caso da percepção ambiental, o pesquisador, frequentemente, é conhecedor do ambiente em foco e tem contato com ele, tanto do ponto de vista de sua própria subjetividade quanto do ponto de vista objetivo (de acordo com sua área de atuação), o que pode diferir sensivelmente do ambiente percebido pelos sujeitos participantes da pesquisa, a partir de suas distintas vivências. Para a fenomenologia, não há oposição entre sujeito e objeto, considerados de modo isolado, mas entre sujeitos e objetos que se constituem de forma interdependente (Bello, 2004; Zilles, 2007).

Para Moreira (2002), a primeira característica a ser considerada por ocasião da adaptação do método fenomenológico em pesquisas empíricas e, mais propriamente, às concessões a serem realizadas diz respeito ao acesso do pesquisador à experiência alheia. Obviamente, a experiência comunicada, habitualmente, por meio de relatos verbais já consiste, em si, num dado de "segunda mão", como expressa esse autor. Porém, como explica Forghieri (2011, p. 19), "possuímos, de certo modo, uma 'comunalidade', pois todos nós vivemos no mundo e existimos uns com os outros, com a capacidade de nos aproximarmos e de compreendermos mutuamente as nossas vivências". De fato, o acesso aos dados se dá no plano intersubjetivo, o que dependerá da estrutura transcendental compartilhada e da entropatia entre pesquisador e sujeito da pesquisa, uma vez que os conteúdos das vivências são individuais, mas a estrutura é comum, o que possibilita a comunicação sobre esses conteúdos (Bello, 2004).

Outro aspecto também destacado por Moreira (2002) e compartilhado por Giorgi (2008) e por Andrade \& Holanda (2010) diz respeito ao emprego das reduções, principal característica do método fenomenológico e condição primordial para que se possa designar qualquer pesquisa como "fenomenológica". O procedimento de redução, por sua vez, conduzirá à identificação das essências acerca do fenômeno estudado, ou seja, da experiência vivida dos sujeitos. Portanto, as estruturas essenciais constituem, juntamente com a redução, os atributos elementares da pesquisa fenomenológica.

Especificamente nos casos de pesquisa empírica, Giorgi (2008) compreende que as essências dependem da perspectiva da disciplina, podendo variar também em quantidade, pois “"[...] é provável que uma pesquisa comportando vários sujeitos dê origem a diversas estruturas típicas, mais do que uma única" (Giorgi, 2008, p. 401). Logo, no campo da percepção ambiental, o conjunto de essências dirá respeito aos diferentes sentidos das vivências ambientais do grupo de participantes.

A questão da amostra, nessa perspectiva, adquire destaque na fase de planejamento da pesquisa empírica que pretende adotar o método fenomenológico como referência. Moreira (2002) explica que o tamanho ideal das amostras é geralmente pequeno, de até 10 sujeitos. Já em seus exemplos de estudos aplicados, o número de sujeitos varia um pouco mais, porém, não ultrapassando duas dezenas, mesmo número apontado por Gil (2010). Este autor indica que "essa estimativa depende dos objetivos do estudo, da natureza do tópico, da quantidade e qualidade das informações pretendidas dos participantes e do número de vezes que serão submetidos a entrevistas" (Gil, 2010, p. 8). Em todos os casos, prima-se pela qualidade e pelo aprofundamento da abordagem com poucos sujeitos ao invés de um número maior, porém, explorado superficialmente.

Por outro lado, resgatando-se Giorgi (2008), considera-se que, quanto maior o número de su- 
jeitos, maior tende a ser a variedade de essências identificadas, motivo pelo qual se deve ter cuidado com amostras muito pequenas. Contudo, independentemente do tamanho da amostra e da técnica de amostragem, a própria natureza subjetiva dos resultados alcançados ao término da pesquisa limita as possibilidades de generalização de suas conclusões, permanecendo restrita ao grupo de participantes. A esse respeito, Moreira (2002) reflete sobre a possibilidade de uma generalização lógica ou naturalística, diversamente de uma generalização estatística dos resultados, o que guarda alguma semelhança com os estudos de caso.

De qualquer maneira, os cuidados não se restringem ao plano da amostra, quando se busca assegurar a validade e o rigor dos resultados obtidos com as pesquisas sob esse tipo de orientação. Trata-se, nesse sentido, da postura geral do pesquisador, de suas experiências prévias com investigações com foco na subjetividade e de outros aspectos operacionais que podem implicar riscos não exclusivos para a pesquisa fenomenológica, mas comuns a outros métodos qualitativos e até mesmo quantitativos, em certa medida (Whyte, 1977; Moreira, 2002).

Retomando a questão das variantes do método fenomenológico, Moreira (2002) demonstra as adaptações construídas por diferentes estudiosos no campo da pesquisa empírica, tais como Van Kaam, Colaizzi, Sanders e Giorgi. Desse grupo, selecionamos o método de Giorgi $(1985 ; 2008)$ para aplicação no campo da percepção ambiental, tendo sido produzidos alguns trabalhos, ainda que com características exploratórias, no âmbito do Programa de Pós-Graduação em Ciências do Ambiente da Universidade Federal do Tocantins (UFT). Os resultados desses estudos ilustram este artigo.

De acordo com o método de Giorgi (1985; 2008), o procedimento se inicia pela coleta de narrativas ou de descrições verbais acerca de expe- riências específicas dos sujeitos, com base em uma questão norteadora. Nesse caso, interessar-nos-ão as experiências dos sujeitos em relação ao meio ambiente, havendo, normalmente, uma delimitação enunciativa em torno de um ambiente específico, como uma cidade, um bairro, um local turístico ou outro escolhido.

Uma vez realizada a coleta, por meio da gravação de áudio e transcrição fiel do material, Giorgi (2008) sugere inicialmente uma leitura ampla dos dados, capaz de revelar sua significação global, o que, posteriormente, possibilitará ao pesquisador tematizar esses dados à luz de sua disciplina e dos objetivos de sua investigação. Depois disso, os dados são divididos em unidades de significação ou em recortes de interesse para a pesquisa, que podem corresponder a um determinado trecho da descrição ou até mesmo a uma frase dela. Essa etapa permite ao pesquisador "[...] ficar mais próximo dos dados, do que se ele tentasse apreendê-los em sua totalidade" (Giorgi, 2008, p. 399).

Todavia, Giorgi (2008) explica que se deve ter o cuidado de não se procurar nos dados, ao recortá-los, apenas alguns pontos específicos do que se espera ou se acredita, a partir de certos critérios eleitos, o que significaria alimentar uma hipótese e, consequentemente, contradizer um princípio fundamental do método fenomenológico (epoché). Sendo assim, é preciso estar aberto para descobrir os sentidos presentes nos dados e dar possibilidade para a revelação de significados imprevistos, o que é próprio da subjetividade. A esse respeito, Andrade \& Holanda (2010, p. 262) explicam que “[...] o pesquisador fenomenólogo coloca-se em posição orientada para a descoberta, ou seja, põe-se aberto para qualquer tipo de conteúdo ou tema que venha a emergir na sua pesquisa".

A etapa seguinte diz respeito à adoção da redução pelo pesquisador, quando se busca a enunciação 
dos dados brutos na linguagem da disciplina. Nesse ponto, conforme Giorgi (2008), a descrição deve ser a mais pura possível, mantendo-se o caráter perceptivo do sujeito, porém, empregando-se a forma de expressão científica do pesquisador. Para Andrade \& Holanda (2010), as descrições devem ser interrogadas, buscando-se manter a fidelidade ao sentido expresso pelo narrador. Nesse ponto, os dados são apresentados em um determinado contexto, e o seus sentidos começam a aparecer; o enunciado se particulariza no âmbito da disciplina e do tema da pesquisa. $\mathrm{O}$ aspecto descritivo passa, gradualmente, a exprimir um viés explicativo/interpretativo, como requer a perspectiva de uma investigação empírica (Giorgi, 2008).

Por fim, chega-se à síntese dos resultados, pela identificação das essências contidas em todas as unidades de significação previamente reduzidas. Nessa fase, procura-se por aquilo que é fundamental (essencial) no fenômeno para sua designação, segundo um procedimento de variação livre e imaginária. Tal processo fornece elementos para o reconhecimento de estruturas essenciais, que correspondem aos diferentes modos pelos quais o objeto é percebido ou vivenciado pelos sujeitos. Faz-se, com isso, uma trajetória do fenômeno experienciado às significações, e das significações às estruturas essenciais (Giorgi, 2008). Por essa via, portanto, os sentidos da percepção são revelados a partir dos próprios sujeitos, oferecendo-se um rico panorama a respeito de como o fenômeno se manifesta às suas consciências.

Entende-se, todavia, que a aplicação do método fenomenológico não esgota as possibilidades de investigação sobre o fenômeno, sobretudo se considerarmos as demais formas de abordagem previstas por Whyte (1977) para os estudos em percepção ambiental. Isso também coaduna com o caráter de flexibilidade do método e o uso de outras técnicas para coleta de dados que redundam desse contexto (Gil, 2010). Logo, a partir das essências reveladas com a ajuda do método fenomenológico, tem-se a possibilidade de aprofundamento das pesquisas, com base no emprego de estratégias complementares, tais como o "perguntando" e o "observando" de Whyte (1977), com suas respectivas técnicas.

Os resultados obtidos por meio da investigação fenomenológica, nessa perspectiva, poderão orientar os procedimentos seguintes, cumprindo um papel que, normalmente, é desempenhado pela figura da hipótese, no campo das pesquisas ambientais. Assim, a construção de um roteiro de questões para uma entrevista dirigida ou de um guia para observação em campo não se fará a partir de concepções prévias do pesquisador a respeito do tema investigado, mas a partir da subjetividade revelada pelos próprios participantes (sujeitos) da pesquisa.

Considera-se, desse modo, que os instrumentos convencionais de pesquisa qualitativa (questionário, entrevista, observação e afins) costumam refletir a hipótese e a visão de mundo do pesquisador, prestando-se muito mais à verificação do que à descoberta (Moreira, 2002). Porém, no caso de sua aplicação atrelada ao método fenomenológico, sua função de verificação poderá ser cumprida com a própria validação das essências identificadas nas descrições ou nas narrativas dos sujeitos, não necessariamente das hipóteses e teorias previamente definidas pelo pesquisador, de modo semelhante ao procedimento adotado por Colaizzi (1978, citado por Moreira, 2002). Tal validação reveste-se também de um aspecto ético em relação aos participantes das pesquisas, de modo que possam, de alguma sorte, ratificar o processo de redução e as essências identificadas na fase anterior. Além disso, tem-se a oportunidade para o aprofundamento e o esclarecimento de alguns pontos não suficientemente elucidados nos dados verbais, coletados inicialmente. 
Esse tipo de refinamento da investigação, fundamentalmente no campo da percepção ambiental, certamente se revestirá de grande significância se for considerado o caráter empírico das pesquisas, bem como a busca por resultados pragmáticos, o que é natural do ponto de vista científico. Tal tarefa não se configura destituída de riscos, em decorrência da qualificação fenomenológica perseguida pelos trabalhos mencionados neste artigo e das especificidades inerentes a esse tipo de método, especialmente se pensado a partir de suas concepções filosóficas originais. Porém, como bem explicado por Moreira (2002), a transposição do método fenomenológico para o domínio da pesquisa empírica não pode acontecer sem ajustamentos, o que torna a empreitada desafiadora, ainda que repleta de oportunidades e desdobramentos, particularmente para o domínio da percepção ambiental.

\section{Exemplos de aplicação: trajetórias metodológicas e resultados alcançados}

Conforme mencionado, pretende-se apresentar como exemplo a articulação do método fenomenológico norteado por Giorgi (1985; 2008) em pesquisas ambientais de orientação perceptiva desenvolvidas no escopo do Programa de Pós-Graduação em Ciências do Ambiente da UFT. Dessa maneira, os trabalhos de Teixeira (2012) e de Silva (2012) constituem frutos dessa linha de raciocínio, comportando trajetórias metodológicas e resultados ilustrativos que permitem uma avaliação preliminar dos esforços até aqui empreendidos.

Teixeira (2012) dirigiu sua investigação às práticas ambientais e associativas desenvolvidas por uma comunidade quilombola do Estado do Tocantins, denominada Comunidade Quilombola Barra da Aroeira. Trata-se de um grupo remanescente, localizado na zona rural do Município de Santa Teresa do Tocantins, a cerca de $100 \mathrm{~km}$ a leste de Palmas, devidamente reconhecido pela Fundação Cultural Palmares e composto por 86 famílias. Essa comunidade se sustenta especialmente da agricultura e do processamento dos seus produtos, por meio do emprego de técnicas tradicionais, tais como a produção de hortaliças, de farinha e de rapadura. Criada em 2004, a Associação Comunitária dos Quilombos da Barra da Aroeira vem buscando representar os interesses dos moradores, viabilizando o acesso a benefícios sociais e a incentivos públicos, além de organizar a produção local e facilitar a sua comercialização fora da comunidade.

Para a execução da pesquisa fenomenológica referente à abordagem “ouvindo" de Whyte (1977), Teixeira (2012) trabalhou com 17 sujeitos, entre os quais foram escolhidas inicialmente duas lideranças locais e, posteriormente, outros sujeitos selecionados aleatoriamente nas moradias. Um dos desafios encontrados para a construção desse corpus empírico se relacionou à livre adesão e à desenvoltura dos sujeitos para proceder às descrições verbais, o que pode estar relacionado com a sua timidez e a inexperiência com situações semelhantes de envolvimento e de colaboração com pesquisas, entre outros fatores.

A relação de confiança entre o pesquisador e os sujeitos constitui, a nosso ver, um ponto ainda carente de amadurecimento no âmbito da pesquisa fenomenológica empírica. Por um lado, em situações de desconfiança, as descrições poderão passar por autocensura do sujeito, levando-o a omitir informações ou a distorcer a descrição. Por outro, quando a confiança demanda um longo contato antecedente com o grupo de sujeitos (comum em pesquisas etnográficas, por exemplo), o possível conhecimento sobre detalhes da pesquisa também poderá introduzir vieses nas descrições. 
No caso de Teixeira (2012), por se tratar de uma comunidade quilombola rural e com a qual não se tinha vínculos prévios, obviamente foram necessárias incursões a campo anteriores à coleta das descrições, o que envolveu contatos com lideranças e com o próprio território quilombola, buscando-se manifestar, em linhas gerais, os propósitos da investigação e construir alguma empatia com a comunidade. Assim, buscou-se obter um relativo equilíbrio entre os critérios expostos, para que a coleta das descrições transcorresse com êxito, possibilitando obter material capaz de subsidiar satisfatoriamente a investigação.

Ainda assim, em alguns casos, descrições excessivamente lacônicas foram descartadas, mesmo procedimento adotado quando interferências de outras pessoas no momento da coleta (parentes, vizinhos etc.) acabavam por introduzir vieses na descrição dos sujeitos, comprometendo a sua natureza e leitura fenomenológica ou, em outras palavras, o caráter do fenômeno ou da experiência conforme manifestado à consciência.

Por conta de todas essas características, o êxito depende, em grande medida, da habilidade do pesquisador. Este, por exemplo, poderá adotar uma postura encorajadora sem, contudo, interferir no conteúdo da descrição no momento de sua coleta. Deverá também fazer uso de sua capacidade de discernimento sobre a qualidade e a fidelidade dos resultados obtidos com as descrições, visando descartar o que for desnecessário.

No trabalho de Teixeira (2012), a coleta de descrições verbais vinculou-se a dois objetos específicos: os aspectos da natureza na área da comunidade e a associação comunitária. Como o intuito era o ouvir os sujeitos e não proceder a uma entrevista, os enunciados foram formulados de maneira que não se configurassem como perguntas, mas pedidos, em uma linguagem acessível, para que descreves- sem o fenômeno indicado, conforme suas próprias experiências. É óbvio que as descrições partiram de uma atitude natural dos sujeitos e que coube ao pesquisador a adoção da atitude fenomenológica mediante o manuseio e a leitura do material obtido (aplicação do método), conforme já explicado por Moreira (2002).

As descrições livres foram gravadas e em seguida transcritas, passando a constituir o material básico para a aplicação do método, conforme definido por Giorgi (1985; 2008). Das transcrições, devidamente lidas e inspecionadas em seu conjunto, foram selecionadas as diferentes unidades de significação, considerando-se as mudanças de sentido ao longo de cada descrição, sem perder de vista a temática da pesquisa, a exemplo dos trechos que se seguem:

A natureza oferece tudo de bom, primeiramente tem o buriti, né, que serve de alimentação e também artesanal. A macaúba serve para bastante coisa, para alimentar porco, para alimentar nós e também da macaúba a gente tira o óleo ao invés da manteiga da loja que é a mesma coisa agente utiliza no beiju para quebrar o jejum de manhã. A natureza oferece também o pequi que é uma comida muito especial para nós quilombolas e também do pequi a gente tira o óleo que serve de remédio, faz o sabão também. Menino, se a gente for falar tudo o que a natureza oferece (risos)... Dá vontade de chorar quando a gente vê aquelas grandes derrubadas destruindo a natureza. Dá vontade de chorar porque quanto pé de pequi que vai, pé de murici, mangaba e assim por diante, mas fazer o que né? (I. R., descrição da natureza, gravada em 20/12/2010).

A associação, pro meu ponto de vista, tem sido um braço direito da comunidade. Através da associação outra hora muitas mulheres não tinham conseguido receber o salário-maternidade. E também sobre os nossos direitos. A associação tem sido a fonte de vida. O que eu tenho a dizer sobre a associação é isso mesmo. O que a gente luta é para que ela nunca se 
acabe, ela não se enfraqueça, fique mais forte. Tem bastante gente participando, não só os associados, mas que são da comunidade (I. R., descrição da associação comunitária, gravada em 20/12/2010).

Em seguida, cada unidade de significação passou pelo processo de redução, sendo agora enunciada segundo uma linguagem formal, considerando-se, nesse caso, as perspectivas da Economia Ecológica e da Economia Solidária, que forneceram o amparo teórico para a pesquisa de Teixeira (2012). Nessa fase da aplicação do método, verificou-se a necessidade de especial atenção à fidelidade em relação à descrição original, por vezes sendo necessárias novas leituras e correções até se obter a melhor redução possível. De todo modo, percebe-se que, nesse quesito, o exercício leva ao aperfeiçoamento gradual do procedimento de redução, o que reforça especialmente o aspecto da experiência ou da iniciação prévia do pesquisador em relação ao método fenomenológico.

As reduções a seguir, referentes às mesmas descrições anteriormente apresentadas, ilustram os produtos obtidos nessa etapa da aplicação do método:

O sujeito descreve que a natureza possibilita inúmeras alternativas para a subsistência, como as frutas (buriti, macaúba e pequi) utilizadas para a alimentação e também para fins medicinais. Faz referência ao significado especial do pequi para a alimentação dos quilombolas. Demonstra profundo pesar com os impactos sobre a natureza, embora indicando [demonstrando] resignação (Redução referente à descrição da natureza por I. R.).

O sujeito aborda com entusiasmo a associação, enfatizando seu importante papel para a comunidade e o seu desenvolvimento. Ressalta que, por meio da associação, passaram a acessar benefícios sociais, como o salário-maternidade. Fala sobre a função da associação em relação aos direitos dos moradores e afirma seu desejo pela continuidade e fortalecimento da prática associativa (Redução referente à descrição da associação comunitária por I. R.).

Finalmente, do conjunto de reduções foram identificadas as essências, procurando-se recolher aquilo que fosse considerado fundamental no fenômeno descrito por cada sujeito. Esse passo, por sua vez, deu origem à Tabela 1 , por meio da qual podem ser observadas as estruturas essenciais, referentes aos dois aspectos abordados por Teixeira (2012). Nota-se que há diferentes estruturas, indicando diferentes modos de percepção ou de manifestação dos fenômenos à consciência, os quais, por sua vez, estão relacionados a diferentes tipos de relação entre sujeito e objeto, dentro do corpus empírico da pesquisa.

Em virtude do caráter metodológico deste artigo, não é de nosso interesse discutir os resultados alcançados por Teixeira (2012), sendo que maiores detalhes a esse respeito poderão ser encontrados também em Teixeira \& Souza (2011; 2016). Logo, o foco é demonstrar os procedimentos adotados pelo autor, especialmente no que tange à utilização do método de fenomenologia empírica de Giorgi $(1985 ; 2008)$ e suas possibilidades de articulação com outras estratégias de pesquisa. Como apontado, Teixeira (2012) estruturou sua investigação por meio do triângulo de Whyte (1977), tendo a abordagem fenomenológica constituído a etapa inicial da pesquisa, quando o sentido geral da percepção dos sujeitos ainda se fazia totalmente desconhecido.

Sendo assim, a partir da identificação das estruturas essenciais, Teixeira (2012) prosseguiu com seu inquérito, passando a adotar outras técnicas de pesquisa, dessa vez, ligadas às abordagens "perguntando" e "observando", de Whyte (1977). Tais abordagens, contudo, foram esboçadas a partir dos 
TABELA 1 - Essências identificadas nas descrições dos sujeitos da Comunidade Quilombola Barra da Aroeira, quanto à natureza e à associação comunitária.

\begin{tabular}{|c|c|c|}
\hline \multicolumn{3}{|l|}{ Natureza } \\
\hline Essências & $\begin{array}{c}\text { Descrições } \\
\left(\mathbf{n}^{0} \text { dos sujeitos }\right)\end{array}$ & Frequência \\
\hline Natureza como fonte de subsistência & $\begin{array}{c}1,2,3,4,5,6,7,8,9,10,11 \\
12,13,14,15,16 \text { e } 17\end{array}$ & 17 \\
\hline Preocupação com o manejo ambiental & $1,7,8,10,11$ e 13 & 6 \\
\hline Preocupação com a sustentabilidade & $1,2,3$ e 4 & 4 \\
\hline Preocupação com os impactos ambientais & 1,3 e 17 & 3 \\
\hline Resiliência frente às restrições ambientais & 8,9 e 14 & 3 \\
\hline Facilidade atual para o cultivo da terra & 6 & 1 \\
\hline Trabalho para o cultivo da terra & 5 & 1 \\
\hline Resignação frente aos impactos ambientais observados & 11 & 1 \\
\hline \multicolumn{3}{|l|}{ Associação Comunitária } \\
\hline Essências & $\begin{array}{c}\text { Descrições } \\
\left(\mathrm{n}^{0} \text { dos sujeitos }\right)\end{array}$ & Frequência \\
\hline Promoção de desenvolvimento local & $\begin{array}{c}4,5,6,7,8,9,10,11,12,13 \\
14,15,16 \text { e } 17\end{array}$ & 14 \\
\hline Preocupação com a política na condução da Associação & 1 & 1 \\
\hline Representação da comunidade em relações externas & 2 & 1 \\
\hline Crítica em relação à gestão atual & 3 & 1 \\
\hline Avaliação positiva das reuniões da associação & 3 & 1 \\
\hline Preocupação com a continuidade da associação e com a participação dos moradores & 11 & 1 \\
\hline Associação como fator para melhoria da autoestima da comunidade & 16 & 1 \\
\hline
\end{tabular}

FONTE: adaptado de Teixeira (2012, p. 48; 63).

próprios sentidos revelados inicialmente pelos sujeitos e pelo consequente esclarecimento do fenômeno na perspectiva de quem o vivencia. Isso resultou em questões e em focos de observação sensivelmente diferentes daqueles que seriam projetados no caso da ausência de utilização do método fenomenológico, na primeira parte da pesquisa.

Em caráter ilustrativo, Teixeira (2012) buscou detalhar, por meio de entrevistas ("perguntando"): as práticas de conservação da natureza no âmbito da comunidade; os impactos ambientais no território quilombola e suas consequências para os moradores; o papel prático da associação comunitária em sua vida cotidiana; os avanços já obtidos por meio da associação e aqueles desejados para o futuro, entre outros aspectos. Já por meio de observação direta e indireta ("observando"), o autor procurou conhecer: as técnicas de manejo ambiental na produção agrícola e no processamento artesanal da produção; a participação e o envolvimento dos moradores em eventos promovidos pela associação comunitária e, ainda, meios de identificar possíveis indicadores de impacto ambiental no território quilombola, por exemplo. Nesse caso, tanto a condução da investigação quanto o resultado alcançado mostraram-se profundamente afetados, num bom sentido, pela utilização do método fenomenológico.

Outro exemplo de trabalho que buscou esse tipo de articulação foi o de Silva (2012), ainda que seu enfoque estivesse voltado para um tema bastante diferente: o planejamento e a gestão do meio ambiente urbano, em Palmas (TO), a partir da 
percepção de gestores e técnicos ligados ao poder público municipal. Partindo da consideração de que a maior parte dos estudos de percepção ambiental em áreas urbanas toma como sujeitos os cidadãos e usuários dos diferentes espaços da cidade, Silva (2012) procurou compreender o tema por outro prisma. Em outras palavras, a autora procurou verificar como os problemas ambientais urbanos são percebidos por aqueles que lidam diretamente com a questão e dos quais normalmente se espera por soluções. A cidade de Palmas, apesar do status de "cidade planejada", convive com diversos problemas ambientais, como a disposição irregular de resíduos sólidos em vazios urbanos e os alagamentos, estes em função de deficiências de drenagem.

Assim como Teixeira (2012), Silva (2012) partiu do pressuposto de "ouvir" seus sujeitos, em um primeiro momento, baseando-se no esquema de Whyte (1977) e empregando o método fenomenológico de Giorgi $(1985 ; 2008)$ na etapa inicial da pesquisa. Para tanto, o corpus empírico dessa fase do estudo foi formado por um total de 10 sujeitos, entre gestores (com cargos de direção e coordenação) e técnicos, cujas atividades, no âmbito da Prefeitura Municipal de Palmas, estivessem direta ou indiretamente ligadas a questões ambientais urbanas.

O grupo abordado por Silva (2012) apresentou características bastante distintas daquele abordado por Teixeira (2012), tendo sido formado por indivíduos com maior escolaridade (todos com nível superior em diferentes áreas), residentes na área urbana de Palmas (TO) e servidores públicos. Assim, foi possível observar, em linhas gerais, melhor fluência verbal e menor inibição para colaborar com a pesquisa, resultando em um maior volume de material coletado.

A coleta do material (em áudio) foi realizada individualmente em locais reservados dos próprios órgãos públicos, após a devida autorização e mediante agendamento prévio. Tal procedimento permitiu que não houvesse interferências de terceiros nos conteúdos gravados, auxiliando também na qualidade do material obtido e evitando possíveis descartes.

Foi solicitado a cada sujeito que abordasse livremente a questão do planejamento e da gestão ambiental urbana na cidade, descrevendo-os; suas falas gravadas foram posteriormente transcritas. Pelas condições mencionadas, obteve-se um volume considerável de transcrições, demandando maior tempo e atenção para o procedimento seguinte. Após a leitura completa e o reconhecimento do sentido de todo o conjunto transcrito, selecionaram-se as unidades de significação, considerando-se a temática da pesquisa, a exemplo do trecho que segue:

Aqui é uma Secretaria (do meio ambiente) que tá limitada, que não tem um foco definido, muda de nome a toda hora, né. E essa intersetorialidade, por exemplo, da Saúde que é um dos focos principais da gestão ambiental, não existe no município. Não existe intersetorialidade, trans-setorialidade, nem interdisciplinaridade no município de Palmas. É cada Secretaria funcionando com sua metodologia de trabalho e esse é um dos pontos negativos do município, né. É que a rede de gestão do ambiente, ela não tá formada. Então trabalha sozinha a Secretaria do Meio Ambiente, trabalha sozinha a Secretaria de Infraestrutura, a Secretaria de Educação e a Secretaria de Saúde [...] Nós não conseguimos, por exemplo, trabalhar com outras secretarias dentro da prefeitura, que é o que precisaria pra ter realmente uma gestão do ambiente, e esta gestão não está de acordo com o Plano Diretor no município (M. S., descrição sobre o planejamento e a gestão ambientais urbanas em Palmas, gravada em 12/08/2011).

$\mathrm{Na}$ sequência, as unidades de significação passaram pelo procedimento de redução, conforme estabelecido por Giorgi (1985; 2008). Nessa fase, 
procurou-se adotar uma linguagem formal oriunda das áreas de Planejamento Urbano e Ambiental, principais bases teóricas adotadas por Silva (2012), mantendo-se, porém, o sentido original dado pelos sujeitos. Os cuidados tomados quanto à fidelidade entre unidades de significação e suas respectivas reduções, bem como o seu exercício de aprimoramento, foram os mesmos de Teixeira (2012).

O exemplo a seguir ilustra os resultados do procedimento de redução, tomando-se como referência a mesma descrição antes apresentada:

O sujeito aponta instabilidades ligadas à linha de trabalho e à própria designação da Secretaria de Meio Ambiente como fatores que comprometem sua atuação. Afirma que a gestão ambiental não é realizada de maneira integrada entre as secretarias municipais, mas de modo desarticulado, não havendo um trabalho em rede. Salienta que a gestão ambiental, como vem sendo feita, está em desacordo com os princípios do Plano Diretor de Palmas (Redução referente à descrição sobre o planejamento e a gestão ambientais urbanas em Palmas por M. S.).
Por último, Silva (2012) passou à identificação das essências presentes no conjunto de reduções, buscando reconhecer os elementos invariáveis do fenômeno, conforme percebido pelos sujeitos e comunicado por meio de suas descrições. A autora chegou, com esse procedimento, às estruturas essenciais relativas ao planejamento e à gestão ambiental urbanos em Palmas, segundo a percepção dos gestores e técnicos municipais envolvidos com esse tipo de trabalho e que compuseram o corpus empírico da pesquisa (Tabela 2).

Assim como manifestado no caso da pesquisa de Teixeira (2012), os resultados obtidos por Silva (2012) não serão aqui discutidos, sendo que também podem ser encontrados em Silva \& Souza (2014). Porém, cabe ressaltar que a variedade de estruturas essenciais (12) identificadas por Silva (2012) chegou a superar o próprio número de sujeitos (10), o que revela a pluralidade de percepções sobre o fenômeno em tela. Tal característica pode estar relacionada a fatores como a diversidade de formação

TABELA 2 - Essências identificadas nas descrições dos gestores e técnicos da Prefeitura Municipal, quanto ao planejamento e à gestão ambiental urbanos em Palmas.

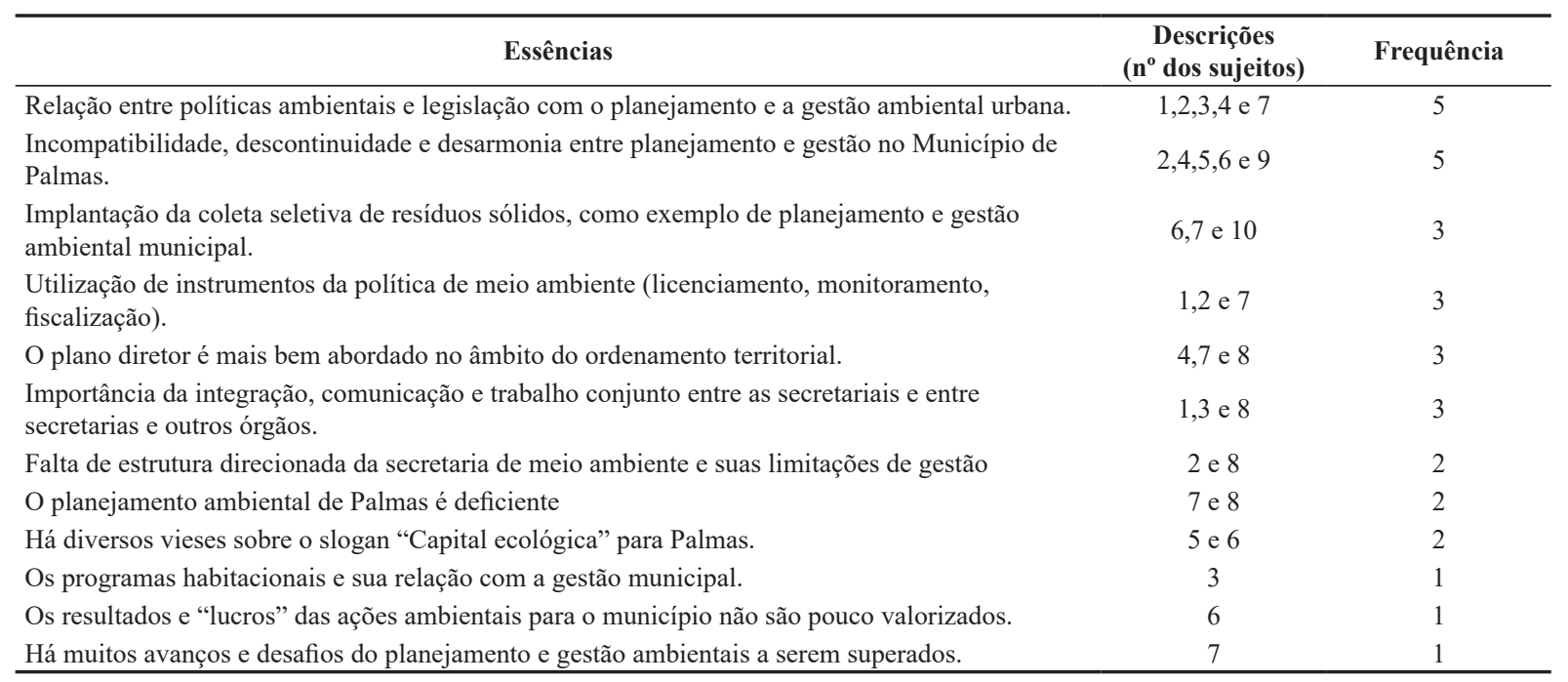

FONTE: adaptado de Silva (2012, p. 81). 
profissional entre os sujeitos e ao fato de trabalharem em diferentes secretarias e órgãos da Prefeitura de Palmas, o que pode conferir diferentes tipos de relação entre o sujeito e o objeto da percepção.

Tais estruturas essenciais, obtidas por meio da utilização do método fenomenológico de Giorgi (1985; 2008), forneceram os referenciais para o aprofundamento da pesquisa de Silva (2012), mediante a formulação de roteiros de entrevistas que foram aplicados num segundo momento da investigação. Esse novo procedimento, referente à abordagem "perguntando" de Whyte (1977), somente foi pensado a partir da revelação dos sentidos, por parte dos sujeitos, do fenômeno por eles percebido.

Como exemplos dos tópicos abordados por Silva (2012) nas referidas entrevistas, podem-se destacar: a percepção dos sujeitos sobre a articulação entre o planejamento e a gestão no Município de Palmas; a relação do trabalho individual desenvolvido pelos sujeitos com o Plano Diretor de Palmas (Palmas, 2007); os principais problemas ambientais urbanos da cidade; exemplos de sucesso e de fracasso no planejamento e na gestão ambiental urbana no município; o trabalho coordenado entre secretarias e órgãos municipais, bem como a continuidade de políticas públicas no campo ambiental urbano e, por fim, a influência da estrutura organizacional do poder municipal nesse mesmo quesito.

A sequência das estratégias de pesquisa mostrou-se, assim, fundamental para a pesquisa de Silva (2012), considerando o método fenomenológico como processo revelador das essências perceptivas dos sujeitos. Tem-se, assim, a partir de uma atitude inicial de suspensão, uma maior abertura por parte do pesquisador, que deixa de lado, ao menos temporariamente, suas hipóteses e sua própria visão de mundo, para se permitir à oportunidade da descoberta.

\section{Considerações finais}

A proposta de pesquisa, cujas reflexões e procedimentos metodológicos foram aqui compartilhados, tem se mostrado, até o momento, um caminho apropriado para o alcance dos objetivos traçados pelas investigações ora concluídas ${ }^{1}$ e por outras ainda em curso. Trata-se de pesquisas perceptivas com enfoque ambiental, caráter interdisciplinar e atreladas pelo compromisso comum da abordagem fenomenológica e de sua articulação com outras técnicas convencionais de pesquisa qualitativa empírica.

$\mathrm{O}$ fato de ter-se empregado o método adaptado por Giorgi (1985; 2008) não invalida a possibilidade de que outras variantes do método fenomenológico sejam também testadas e avaliadas, em sua adequação, aos princípios e objetivos dos estudos perceptivos ambientais. Assim como mencionado, Andrade \& Holanda (2010), Gil (2010) e, principalmente, Moreira (2002) abordam essas variantes, demonstrando que a adaptação do método à pesquisa empírica comporta diferentes interpretações e concessões em relação ao que fora pensado originalmente na Filosofia.

Entretanto, o uso do método fenomenológico fora do domínio filosófico não corresponde a um caminho ameno e destituído de riscos, dadas as dificuldades impostas por seus elementos genéticos, além de sua complexidade. Tais dificuldades se ini-

\footnotetext{
${ }^{1}$ Além dos trabalhos de Teixeira (2012) e de Silva (2012), examinados neste artigo, os trabalhos de Santos (2013) e de Rocha (2014) também foram concluídos usando metodologias semelhantes, envolvendo a aplicação do método fenomenológico, segundo a variante de Giorgi (1985; 2008), em articulação com outras técnicas de pesquisa qualitativa, no campo da percepção ambiental.
} 
ciam na própria formação acadêmica da maioria dos estudantes de graduação, especialmente em cursos relacionados à área ambiental, uma vez que, nessa fase, praticamente não há contato com conteúdos e métodos filosóficos, como a Fenomenologia. Isso faz com que a iniciação seja tardia, muitas vezes já em nível de pós-graduação, encurtando o tempo precioso para o conhecimento da teoria e o razoável domínio do método e do vocabulário fenomenológicos, imprescindíveis a qualquer exercício para a sua adaptação empírica.

Ressalte-se, nesse contexto, o diferencial representado pela aptidão pessoal e pela dedicação sistemática daqueles interessados em adotar o referido método em suas pesquisas, a começar pelo estudo de escritos filosóficos. Do mesmo modo, ao longo de toda a trajetória de pesquisa, faz-se necessário o exame crítico dos procedimentos empreendidos, bem como da postura do pesquisador ao manejar os seus dados, especialmente se considerada a sua vinculação a um projeto ainda inacabado e, portanto, aberto a possíveis realinhamentos, em nosso caso específico.

Para que uma pesquisa seja qualificada como "fenomenológica", importa que a investigação esteja ancorada em pressupostos básicos, tais como a suspensão de prejulgamentos, o foco no fenômeno percebido ou vivido pelos sujeitos, a coleta sistemática de descrições, a adoção de uma atitude fenomenológica ao lidar com tais descrições, o emprego dos expedientes de redução e a busca por essências ou por estruturas essenciais a respeito do fenômeno percebido. Tais elementos devem permear a concepção e a construção da pesquisa, podendo servir como balizadores para o acompanhamento e a avaliação de trabalhos como o de Teixeira (2012) e o de Silva (2012), exemplificados neste artigo.

A incorporação do método fenomenológico ao plano dos estudos sobre o meio ambiente remete também à questão dos seus critérios científicos, o que é alvo habitual de preocupação na pesquisa empírica. A esse respeito, Moreira (2002) explica que haverá dependência do referencial de interpretação, se propriamente fenomenológico ou, contraditoriamente, positivista. Por esse último prisma, a obtenção de um tipo de conhecimento passível de generalização estatística é especialmente valorizada, considerando-se os moldes científicos tradicionais. Mas, para a Fenomenologia, a validade interna dos resultados acaba sendo mais importante que sua validade externa, o que justifica a preferência do método pelo aprofundamento da abordagem, com vistas ao esclarecimento dos fenômenos, por meio de um número reduzido de sujeitos, por exemplo.

Assim, tal característica representa apenas uma especificidade quanto à natureza do resultado obtido, o que constitui um aspecto virtuoso do método fenomenológico, que se dispõe a compreender a origem do conhecimento, abrindo-se à subjetividade. Contudo, estão longe de se esgotar os esforços de reflexão acerca da construção do corpus empírico nos trabalhos envolvendo o método fenomenológico. Aspectos como a saturação dos conteúdos obtidos por meio das descrições, a pluralidade de sentidos típica da subjetividade e a definição do número de sujeitos em uma investigação continuam merecedores de maior aprofundamento, o que afirmamos com base em nossa experiência de pesquisa.

Outro desafio da adaptação do método fenomenológico à pesquisa empírica diz respeito a sua utilização em grupos de diferentes perfis socioculturais, com destaque para aqueles cuja predisposição para colaborar com a investigação, fornecendo descrições verbais, poderá depender de algum grau de confiança construído. Exemplo disso são os trabalhos com enfoque em comunidades tradicionais, como foi o caso de Teixeira (2012) em uma comunidade quilombola no interior do Tocantins. Deve-se 
pensar, pois, na dicotomia envolvendo aproximação e distanciamento entre pesquisador e sujeitos da pesquisa, por conta dos possíveis vieses a serem introduzidos nas falas que serão a matéria-prima para a aplicação do método.

Por fim, entre todos os ganhos possibilitados pelo método fenomenológico, conforme se procurou demonstrar por intermédio dos dois trabalhos que ilustraram este texto, destacam-se exatamente a abertura aos sentidos revelados pelos sujeitos e o exercício de suspensão (epoché fenomenológica), ao menos inicial, por parte do pesquisador. São esses componentes que poderão levar à formulação de instrumentos e de roteiros de pesquisa mais fiéis ao aspecto fenomênico estudado. Do contrário, todo o desenho prévio da investigação permanece à mercê das hipóteses construídas de modo completamente alheio aos sujeitos da pesquisa e, por outro lado, de- pendentes da visão de mundo e das leituras teóricas do pesquisador. É notório que a adoção do método fenomenológico não esgota as possibilidades da pesquisa ambiental perceptiva, mas pode abrir caminhos para formas menos convencionais de construção do conhecimento a respeito das relações entre os seres humanos e o meio ambiente.

Considerando todos esses pressupostos, nosso trabalho vem também sendo feito a cada nova leitura, seja de autores ligados diretamente à escola fenomenológica, no domínio da Filosofia, seja daqueles que vêm se dedicando à transposição do método para a pesquisa empírica em diferentes ramos científicos ou ainda de autores voltados, mais especificamente, aos estudos da subjetividade no campo ambiental. Um desafio instigante e que, invariavelmente, conduz a novos aprendizados e a reflexões sobre velhas certezas.

\section{Referências}

Andrade, C. C.; Holanda, A. F. Apontamentos sobre pesquisa qualitativa e pesquisa empírico-fenomenológica. Estudos de Psicologia, 27(2), 259-268, 2010. Disponível em: <http:// www.scielo.br/pdf/estpsi/v27n2/a13v27n2.pdf >.

Bello, A. A. Fenomenologia e ciências humanas. Bauru: EDUSC, 2004.

Bello, A. A. Introdução à Fenomenologia. Bauru: EDUSC, 2006.

Dardel, E. O homem e a terra: natureza da realidade geográfica. São Paulo: Perspectiva, 2011.

Del Rio, V.; Oliveira, L. Percepção ambiental: a experiência brasileira. 2. ed. São Paulo: Studio Nobel, 1999.

Depraz, N. Compreender Husserl. 2. ed. Petrópolis: Vozes, 2008. (Série Compreender)

Forghieri, Y. C. Psicologia fenomenológica: fundamentos, método e pesquisas. São Paulo: Cengage Learning, 2011.
Gil, A. C. O projeto da pesquisa fenomenológica. In: Anais do IV Seminário Internacional de Pesquisa e Estudos Qualitativos, Rio Claro, 2010. Disponível em: $<$ http://sepq.org. br/IVsipeq/anais/artigos/44.pdf $>$.

Giorgi, A. Phenomenology and psychological research. Pittsburg: Duquesne University Press, 1985.

Giorgi, A. Sobre o método fenomenológico utilizado como modo de pesquisa qualitativa nas ciências humanas: teoria, prática e avaliação. In: Poupart, J.; Deslauries, J-P.; Grou1x, L-H.; Laperrière, A.; Mayer, R.; Pires, Á. P. (Orgs.). A pesquisa qualitativa: enfoques epistemológicos e metodológicos. Petrópolis: Vozes, 2008. p. 386-409.

Holzer, W. Um estudo fenomenológico da paisagem e do lugar: a crônica dos viajantes no Brasil do século XVI. São Paulo, Tese (Doutorado em Geografia Humana) - USP, 1998.

Husserl, E. Ideias para uma fenomenologia pura e para uma filosofia fenomenológica. 3. ed. Aparecida: Ideias e Letras, 2006. (Coleção Subjetividade Contemporânea) 
Merleau-Ponty, M. Fenomenologia da percepção. 2. ed. São Paulo: Martins Fontes, 1999.

Moreira, D. A. O método fenomenológico na pesquisa. São Paulo: Pioneira Thomson, 2002.

Nogueira, A. R. B. Uma interpretação fenomenológica na Geografia. In: Silva, A. A. D.; Galeno, A. (Orgs.). Geografia: ciência do complexus. 2. ed. Porto Alegre: Sulina, 2008. p. 209-236.

Palmas (Município). Lei Complementar $n^{\circ} 155$, de 28 de dezembro de 2007. Dispõe sobre a política urbana do município de Palmas. Palmas - TO, 2007. Disponível em: $<$ https://www.legisweb.com.br/legislacao/?id=176542>. Acesso em: fev. 2017.

Pickles, J. Phenomenology, science and geography. Cambridge: Cambridge University Press, 1985.

Ribeiro, W. C.; Lobato, W.; Liberato, R. de C. Notas sobre fenomenologia, percepção e educação ambiental. Sinapse Ambiental, 6(1), 42-65, 2009. Disponível em: <http://www. pucminas.br/graduacao/cursos/arquivos/ARE_ARQ_REVIS_ELETR20090930145705.pdf >.

Rocha, M. V. Os assentados e suas percepções: uma proposta de gestão ambiental em assentamentos rurais. Palmas, Dissertação (Mestrado em Ciências do Ambiente) - UFT, 2014.

Santos, F. P. Estudo da percepção da qualidade ambiental urbana no município baiano de Luís Eduardo Magalhães. Palmas, Dissertação (Mestrado em Ciências do Ambiente) - UFT, 2013.

Silva, C. U. T. Planejamento e gestão ambientais urbanos no Município de Palmas (TO): uma abordagem fenomenológica a partir do poder público municipal. Palmas, Dissertação (Mestrado em Ciências do Ambiente) - UFT, 2012.

Silva, C. U. T.; Souza, L. B. Planejamento e gestão ambientais urbanos do município de Palmas (TO): uma abordagem fenomenológica a partir do poder público municipal. Espaço
\& Geografia, 17(2), 347-375, 2014. Disponível em: <http:// www.lsie.unb.br/espacoegeografia/index.php/espacoegeografia/article/view/184/220>.

Sokolowski, R. Introdução à Fenomenologia. São Paulo: Edições Loyola, 2004.

Souza, L. B. Percepção ambiental e a fenomenologia de Husserl: um exercício de reaproximação. In: Silva, V. C. P.; Corcinio Junior, G. F. (Orgs.) Natureza e representações imaginárias. Curitiba: Apris, 2013. p. 35-51.

Stein, E. Exercícios de fenomenologia: limites de um paradigma. Ijuí: Editora Unijuí, 2004. (Coleção Filosofia, 8)

Teixeira, R. F. Uma abordagem fenomenológica sobre as práticas ambientais e associativas na Comunidade Quilombola Barra da Aroeira, Tocantins. Palmas, Dissertação (Mestrado em Ciências do Ambiente) - UFT, 2012.

Teixeira, R. F.; Souza, L. B. Empreendimentos solidários: uma abordagem fenomenológica na associação comunitária dos quilombos da Barra da Aroeira, Santa Teresa do Tocantins (TO). Revista da FAE, 14(2), 114-129, 2011. Disponível em: <http://www.fae.edu/revistafae/edicoes-anteriores.vm>.

Teixeira, R. F.; Souza, L. B. Comunidade quilombola Barra da Aroeira (TO): abordagem fenomenológica das práticas ecológicas. Redes, 21(2), 63-86, 2016. Disponível em: <https://online.unisc.br/seer/index.php/redes/article/ view/4757>.

Tuan, Y. Topofilia: um estudo da percepção, atitudes e valores do meio ambiente. São Paulo: Difel, 1980.

Whyte, A. V. T. Guidelines for fields studies in environmental perception. Paris: Unesco, 1977. (MAB Technical Notes, 5)

Zilles, U. Fenomenologia e teoria do conhecimento em Husserl. Revista da Abordagem Gestáltica, XIII(2), 216221, 2007. Disponível em: <http://pepsic.bvsalud.org/pdf/ $\mathrm{rag} / \mathrm{v} 13 \mathrm{n} 2 / \mathrm{v} 13 \mathrm{n} 2 \mathrm{a} 05 . \mathrm{pdf}>$. 